\title{
Prevalence of cognitive dysfunction and its risk factors in children with chronic kidney disease in a developing country
}

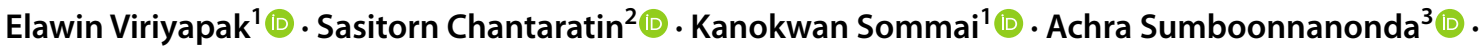

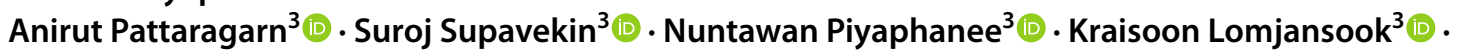 \\ Thanaporn Chaiyapak ${ }^{3}$ (1)
}

Received: 26 February 2021 / Revised: 5 September 2021 / Accepted: 6 September 2021 / Published online: 28 October 2021

(c) The Author(s), under exclusive licence to International Pediatric Nephrology Association 2021

\begin{abstract}
Background Chronic kidney disease (CKD) is associated with cognitive dysfunction. Cognitive function in children with CKD residing in developing countries has not been previously reported.

Methods This cross-sectional study included children aged 6-18 years with CKD stages 2-5D and kidney transplant. Cognitive function was assessed by WISC-V for children from 6-16 years of age. In adolescents 17-18 years of age, WAIS-III was used. Factors associated with cognitive dysfunction were identified using multivariable regression analysis.

Results Thirty-seven children with median age 13.9 (11.3-15.7) years were recruited. The median full-scale intelligence quotient (FSIQ) was 83.0 (71.0-95.0). Below-average cognitive function $(F S I Q<90)$ was identified in 24 children $(64.8 \%)$, $24.3 \%$ of whom had cognitive impairment $(F S I Q<70)$. Most children $(94.6 \%)$ scored lower than average on at least 1 cognitive domain. Kidney replacement therapy $(p=0.03)$ and low family income $(p=0.02)$ were associated with belowaverage cognitive function in multivariable logistic regression analysis. Children who left school and low family income were significantly associated with cognitive function. The FSIQ of children who had left school was 12.94 points lower than the educated group $(p=0.046)$. In addition, every 10,000 Thai Baht (approximately 330 United States dollars) increase in family income correlated with 1.58 increase in $\operatorname{FSIQ}(p=0.047)$.

Conclusion Cognitive dysfunction was commonly found in children with CKD. Socioeconomic factors, particularly school attendance and family income, were associated with cognitive dysfunction. Cognitive evaluation is suggested for children with CKD who have socioeconomic risk factors.
\end{abstract}

Keywords Chronic kidney disease $\cdot$ Cognitive dysfunction $\cdot$ Cognitive impairment $\cdot$ Cognitive deficits $\cdot$ Pediatrics

\section{Introduction}

Children with chronic kidney disease (CKD) are at risk for multidomain cognitive dysfunction [1-3]. Previous studies revealed that children with moderate to severe CKD,

Thanaporn Chaiyapak

thanaporn.cha@mahidol.ac.th; thanaporn0611@gmail.com

1 Department of Pediatrics, Faculty of Medicine, Siriraj Hospital, Mahidol University, Bangkok, Thailand

2 Division of Psychiatry, Department of Pediatrics, Faculty of Medicine, Siriraj Hospital, Mahidol University, Bangkok, Thailand

3 Division of Nephrology, Department of Pediatrics, Faculty of Medicine, Siriraj Hospital, Mahidol University, Bangkok, Thailand including children with CKD stage 5 treated by kidney transplant (KT), had lower cognitive function than siblings and healthy children [4-6]. Central nervous system (CNS) abnormalities have been reported in children with CKD stage 5 and can affect cognitive function [7]. Approximately 12-23\% of children with CKD stage 5, which includes those treated with dialysis and KT, have cerebral atrophy [7]. Furthermore, a recent study in Canada [8] demonstrated that $21 \%$ of children with CKD had cerebral white matter abnormalities on brain magnetic resonance imaging (MRI). In addition to structural CNS abnormalities, several clinical and socioeconomic factors could affect cognitive function.

The prevalence of and risk factors for cognitive dysfunction in children with CKD in previous pediatric studies varied, likely due to differences in cognitive assessment methods, dysfunction definitions, study populations (including 
different age groups and CKD stages), and sample sizes, as well as inconsistent inclusion and exclusion criteria. Several potential clinical risk factors for cognitive dysfunction in children with CKD have been reported, such as greater CKD severity, younger age at kidney disease onset, hypertension, increased blood pressure variability (BPV), proteinuria, anemia, and depression [6, 9-13]. In addition, genetic factors might increase the risk for neurocognitive dysfunction in children with CKD, especially if kidney disease has a clear relationship with a genetic disorder [14]. Children with mild or moderate CKD are also at risk of neurodevelopmental problems [10]. In addition to clinical risk factors, a relationship between low socioeconomic status and cognitive impairment was observed in adults with CKD stage 5D treated with hemodialysis $[15,16]$, but data from children are limited.

Previous studies have investigated cognitive function in children with $\mathrm{CKD}$, but they mainly focused on clinical risk factors $[9,13,17,18]$. A few studies in children with CKD assessed socioeconomic status [10,11], and one study found a relationship between cognitive dysfunction and low maternal education [10]. Additionally, almost all cognitive studies in children with CKD have been conducted in developed countries, where socioeconomic status is different from that in developing countries. To date, cognitive function in children with CKD in developing countries has not been previously reported. According to the World Bank [19], developing countries or low- to upper-middle-income countries are defined as having a gross national income (GNI) $\leq 12,535$ United States dollars (USD). Many children in developing countries are at higher risk of poor health, malnutrition, lack of education, and lack of stimulation at home, all of which affect cognitive development and function [20].

The aim of this study was to determine the prevalence of cognitive dysfunction in both global and specific domains in children with CKD stages 2-5D and KT in a developing country. In addition, the authors aimed to explore both clinical and socioeconomic factors associated with cognitive dysfunction when the full-scale intelligence quotient (FISQ) was lower than the average range $(F I S Q<90)$.

\section{Methods}

\section{Study population}

The study population included all children aged 6-18 years who were diagnosed with CKD stages 2-5D and KT and were clinically stable for at least 3 months at Siriraj Hospital between July 2019 and September 2020. The exclusion criteria were (i) acute illness, (ii) major visual or hearing impairment, (iii) uncontrolled psychosis, and (iv) CNS diseases that significantly affect motor function or higher cortical function. Children who met these criteria were informed of the study, and both parental consent and patient assent were required.

Cognitive assessment The United States (U.S.) version of the Wechsler Intelligence Scale for Children-Fifth Edition (WISC-V), which was published in 2014 and is currently the standard intelligence test for children from 6-16 years of age, was used in this study. This test consists of five primary indexes: the verbal comprehension index, visual spatial index, fluid reasoning index, working memory index, and processing speed index. In adolescents 17-18 years of age, the U.S. version of the Wechsler Adult Intelligence Scale-Third Edition (WAIS-III) was used; this assessment consists of three primary indexes: the verbal comprehension index, working memory index, and processing speed index. Global cognition was expressed as the FSIQ. FSIQs of 110 $119,90-109,80-89,70-79$, and $\leq 69$ were defined as highaverage, average, low-average, very low, and extremely low, respectively.

Cognitive assessments were administered by qualified pediatric psychologists. Below-average cognitive function was defined as an FSIQ lower than 90, and cognitive impairment was defined as an FSIQ lower than 70.

\section{Clinical definition}

For children with congenital kidney disease, the onset of disease was assumed to be the date of birth. The estimated glomerular filtration rate (eGFR) or estimated creatinine clearance $(\mathrm{eCrCl})$ was calculated using the Schwartz formula with an enzymatic method of creatinine measurement [21]. For participants on peritoneal dialysis, the $\mathrm{eCrCl}$ was calculated from 24-h urine and drained dialysate samples [22] and was normalized to $1.73 \mathrm{~m}^{2}$. For children receiving hemodialysis, urea clearance was calculated from the blood and 24-h urine [23] and was normalized to $1.73 \mathrm{~m}^{2}$.

Mild to moderate $\mathrm{CKD}$ was defined as an $\mathrm{eCrCl}$ rate of 30-89 ml/min $/ 1.73 \mathrm{~m}^{2}$ (CKD stages 2-3). Severe CKD was defined as an $\mathrm{eCrCl}$ rate of $<30 \mathrm{ml} / \mathrm{min} / 1.73 \mathrm{~m}^{2}$ with conservative treatment (CKD stages 4-5 without kidney replacement therapy, KRT) [24]. The KRT group included children with CKD stage 5D and KT. According to the World Health Organization (WHO), anemia is defined as serum hemoglobin levels of $<11.5,<12$, and $<13 \mathrm{~g} / \mathrm{dL}$ in children aged 6-11.99 years, children aged $12-14.99$ years, and males $\geq 15$ years old [25]. Hypertension was defined as the use of any antihypertensive medication, and all children in this study who were diagnosed with hypertension were on antihypertensive medication. Proteinuria was defined as a urine protein-to-creatinine ratio (UPCR) greater than 0.2 $\mathrm{mg} / \mathrm{mg}$. Preterm birth was defined as birth at less than 37 weeks of gestation. 
Clinical and socioeconomic characteristics Demographic data were recorded by conducting a parental questionnaire and medical chart review. Laboratory results were collected within 3 months of the cognitive assessment. Socioeconomic data were gathered by parental questionnaires. The primary caregiver was defined as the person who provided direct care and took primary responsibility for children. The primary caregiver may be a parent, or grandparent or other. Financial status was recorded as family income per month. Thai Baht (THB) is the currency of Thailand, and 1 THB was equal to approximately 0.033 USD.

\section{Statistical analysis}

Descriptive statistics were calculated for baseline characteristics. Continuous data are presented as the means ( \pm standard deviations [SDs]) for variables with normal distributions or as medians and interquartile ranges for variables with non-normal distributions. Categorical data are expressed as absolute numbers and percentages. Statistical significance was determined using Pearson's chi-square test or Fisher's exact test for categorical variables and Student's $t$ test or the Mann-Whitney $U$ test for continuous variables, as appropriate. A $p$ value $<0.05$ was considered statistically significant. Factors associated with below-average cognitive function $(F S I Q<90)$ were identified using univariable and multivariable logistic regression analyses. Any variables that were either significant in univariable logistic regression analysis $(p<0.2)$ or clinically significant were selected as candidates for multivariable logistic regression analysis. Final model building for multivariable logistic regression analysis was performed using forward likelihood selection. The clinical factors and socioeconomic factors were obviously different, so multivariable logistic regression analysis was performed separately.

In addition, univariable and multivariable linear regression analyses using the enter method were applied to determine the relationships between risk factors and the FSIQ. All statistical calculations were performed using PASW Statistic (SPSS) 18.0 (SPSS Inc., Chicago, IL, USA).

This study was approved by the Siriraj Hospital Institutional Review Board.

\section{Results}

\section{Demographic and clinical characteristics}

One hundred forty-three children aged 6-18 years who were diagnosed with CKD stages 2-5D and KT from July 2019 to September 2020 at Siriraj Hospital were screened. Of these children, 25 had major visual or hearing impairment and CNS diseases, thus meeting the exclusion criteria. Nineteen children were followed at other hospitals or died. Therefore, 99 children were eligible to participate in this study. The families of 62 of these children declined to participate in this study for several reasons, such as the inconvenience of travel, the avoidance of unnecessary hospital visits during the coronavirus disease 2019 (COVID19) outbreak, and school disruption. Thirty-seven children were included in the study sample.

Baseline demographic and clinical characteristics are summarized in Table 1. The median age was 13.9 (11.3-15.7) years. The most common cause of CKD was congenital anomalies of the kidney and urinary tract (CAKUT). The median eCrCl or urea clearance rate was $41.1(14.3-65.9) \mathrm{ml} / \mathrm{min} / 1.73 \mathrm{~m}^{2}$, and most children (45.9\%) had mild to moderate CKD. The median duration of CKD was 10.0 (2.3-15.8) years. Most children (56.8\%) were using more than 4 medications. Approximately $43 \%$ of the children met the definition for anemia, and 3 children were diagnosed with thalassemia. Approximately half of the children were diagnosed with proteinuria (51.4\%) and hypertension (51.4\%). Only 4 children had a history of preterm birth. None of the children in this study had seizures.

Table 1 Demographic and clinical characteristics of 37 children with chronic kidney disease.

\begin{tabular}{ll}
\hline Characteristics & Number $(n=37)$ \\
\hline Male, $n(\%)$ & $19(51.4 \%)$ \\
Age, years (IQR) & $13.9(11.3-15.7)$ \\
Cause of CKD, $n(\%)$ & \\
Glomerular disease & $8(21.6 \%)$ \\
CAKUT & $24(64.9 \%)$ \\
Others & $5(13.5 \%)$ \\
eCrCL or urea clearance, $\mathrm{ml} / \mathrm{min} / 1.73 \mathrm{~m}^{2}(\mathrm{IQR})$ & $41.1(14.3-65.9)$ \\
Severity of CKD, $n(\%)$ & \\
Mild to moderate CKD & $17(45.9 \%)$ \\
Severe CKD & $6(16.2 \%)$ \\
Dialysis or transplantation & $14(37.8 \%)$ \\
Duration of CKD, years $(\mathrm{IQR})$ & $10.0(2.3-15.8)$ \\
Number of medications $>4, n(\%)$ & $21(56.8 \%)$ \\
Anemia, $n(\%)$ & $16(43.2 \%)$ \\
Proteinuria, $n(\%)$ & $19(51.4 \%)$ \\
Hypertension, $n(\%)$ & $19(51.4 \%)$ \\
History of preterm birth, $n(\%)(n=30)$ & $4(13.3 \%)$ \\
\hline
\end{tabular}

$I Q R$, interquartile range; $C K D$, chronic kidney disease; $C A K U T$, congenital anomalies of the kidney and urinary tract; $\mathrm{eCrCl}$, estimated creatinine clearance 


\section{Socioeconomic characteristics}

Socioeconomic characteristics are summarized in Table 2. Eight $(21.6 \%)$ children left school. The main reasons for children who left school were falling behind academically after frequent school absences, frequent hospital visits, difficulty traveling due to physical disabilities and parental concerns regarding their child's health. The main caregivers were mothers and fathers (83.8\%). Low maternal education $(76.5 \%)$ and low paternal education $(76.7 \%)$ were common in this study. More than half of the children (67.6\%) in this study lived in rural areas. The median monthly family income per household was $20,000(10,000-30,000)$ THB or approximately 660 (330-990) USD.

\section{Cognitive function of children with CKD}

The median FSIQ among all children in this study was 83.0 (71.0-95.0), which was classified as being in the low-average range. The prevalence of below-average cognitive function ( $F S I Q<90)$ was $64.9 \%$ ( 24 children), and $24.3 \%$ (9 children) were considered to have a cognitive impairment $(F S I Q<70)$. Regarding the cognitive domains, the median scores in the

Table 2 Socioeconomic characteristics of 37 children with chronic kidney disease.

\begin{tabular}{ll}
\hline Characteristics & Number $(n=37)$ \\
\hline Children who left school, $n(\%)$ & $8(21.6 \%)$ \\
Maternal data $(\boldsymbol{n}=\mathbf{3 4})$ & \\
Age, years (IQR) & $42.0(35.8-47.3)$ \\
Education, $n(\%)$ & \\
High school or less & $26(76.5 \%)$ \\
Bachelor's degree & $8(23.5 \%)$ \\
Employment, $n(\%)$ & $26(76.5 \%)$ \\
Healthy, $n(\%)$ & $30(88.2 \%)$ \\
Paternal data $(\boldsymbol{n}=\mathbf{3 0})$ & \\
Age, years (IQR) & $43.5(37.8-49.0)$ \\
Education, $n(\%)$ & \\
High school or lower & $23(76.7 \%)$ \\
Bachelor's degree & $7(23.3 \%)$ \\
Employment, $n(\%)$ & $30(100.0 \%)$ \\
Healthy, $n(\%)$ & $29(96.7 \%)$ \\
Main caregiver, $n(\%)$ & \\
Mother or father & $31(83.8 \%)$ \\
Live in rural area, $n(\%)$ & $25(67.6 \%)$ \\
Family income, 10,000 THB ${ }^{\mathrm{a}}(\mathrm{IQR})$ & $2(1.0-3.0)$ \\
\hline
\end{tabular}

$I Q R$, interquartile range; $T H B$, Thai Baht

${ }^{a} 10,000$ THB is equal to approximately 330 United States dollars (USD) visual comprehension, fluid reasoning, and processing speed domains were 72.0 (63.5-86.0), 85.0 (76.8-96.3), and 88.0 (74.5-101.5), respectively, which were lower than the average range $(F S I Q<90)$. Only the scores in the visual spatial (FSIQ 92.0 (81.8-99.3)) and working memory (FSIQ 97.0 (83.5-107.0)) domains were within the average range (FSIQ 90-109). Interestingly, most children (94.6\%) had belowaverage FSIQ $(F S I Q<90)$ scores in at least one cognitive domain. Additionally, approximately half of the children (45.9\%) had scores indicating cognitive impairment (FSIQ $<70$ ) in at least one cognitive domain.

A subgroup analysis was performed to investigate the association between KRT and cognitive function. Fourteen children who underwent KRT were analyzed. Of these children, 8 underwent KT, and 6 were on chronic dialysis. The median FSIQs of children in the chronic dialysis group and the KT group were 84.0 (71.9-87.8) and 70.5 (64.0-89.3), respectively, and there was no statistically significant difference between the two groups ( $p=0.35$ ).

\section{Factors associated with below-average cognitive function}

Several clinical and socioeconomic factors were assessed as potential risk factors for below-average cognitive function $(F S I Q<90)$ in the univariable logistic regression analysis and the calculation of crude ORs (Table 3 ). Among the clinical factors, anemia (OR: 4.88 , 95\% CI: 1.01-23.57, $p=0.049$ ) was a potential factor associated with below-average cognitive function in this study. KRT was more common in the below-average cognitive function group than in the average/above average group (50.0\% vs. $15.4 \%)$. However, this factor was not statistically significant (OR: 5.50, 95\% CI: 0.99-30.29, $p=0.05$ ). Other clinical factors, such as the cause of CKD, duration of CKD, proteinuria, hypertension, and history of preterm birth, were not significantly different between the two groups. Among the socioeconomic aspects, low maternal education (OR: $8.14,95 \%$ CI: $1.32-50.25, p=0.02$ ), low paternal education (OR: $11.88,95 \%$ CI: $1.67-84.52, p=$ 0.01 ), low main caregiver education (OR: $6.56,95 \% \mathrm{CI}$ : $1.05-40.95, p=0.04)$, and low family income $(p=0.02)$ were potential factors associated with below-average cognitive function in this study. There were 24 children who were categorized as having below-average cognitive function, so 2-3 factors could be selected as candidates for the multivariable logistic regression analysis model (10 events per 1 factor). The clinical factors and socioeconomic factors were obviously different, so multivariable logistic regression analysis was performed separately. According to multivariable logistic regression analysis of clinical aspects, anemia ( $p=0.049)$, KRT $(p=0.05$, clinically 
Table 3 Univariable logistic regression analysis and crude odds ratios (ORs) for risk factors for below-average cognitive function in children with chronic kidney disease.

\begin{tabular}{|c|c|c|c|c|}
\hline \multirow[t]{2}{*}{ Characteristics } & \multicolumn{2}{|c|}{$\begin{array}{l}\text { Below-average cognitive function } \\
(F S I Q<90)\end{array}$} & \multirow[t]{2}{*}{ Crude OR $(95 \%$ CI $)$} & \multirow[t]{2}{*}{$P$} \\
\hline & Yes & No & & \\
\hline \multicolumn{5}{|l|}{ Clinical characteristics } \\
\hline \multicolumn{5}{|l|}{ Kidney replacement therapy ${ }^{\mathrm{a}}, n(\%)$} \\
\hline Yes & $12(50.0 \%)$ & $2(15.4 \%)$ & $5.50(0.99-30.29)$ & 0.05 \\
\hline No & $12(50.0 \%)$ & $11(84.6 \%)$ & 1.00 & \\
\hline \multicolumn{5}{|l|}{ Anemia, $n(\%)$} \\
\hline Yes & $13(54.2 \%)$ & $3(23.1 \%)$ & $4.88(1.01-23.57)$ & 0.049 \\
\hline No & $11(45.8 \%)$ & $10(76.9 \%)$ & 1.00 & \\
\hline \multicolumn{5}{|l|}{ Cause of CKD, $n(\%)$} \\
\hline CAKUT & $14(58.3 \%)$ & $10(76.9 \%)$ & $0.35(0.03-3.62)$ & 0.38 \\
\hline Glomerular disease & $6(25.0 \%)$ & $2(15.4 \%)$ & $0.75(0.05-11.31)$ & 0.84 \\
\hline Others & $4(16.7 \%)$ & $1(7.7 \%)$ & 1.00 & \\
\hline Duration of CKD, years (IQR) & $10.0(2.4-14.8)$ & $10.2(3.4-14.3)$ & $1.02(0.90-1.15)$ & 0.81 \\
\hline \multicolumn{5}{|l|}{ Proteinuria, $n(\%)$} \\
\hline Yes & $13(61.9 \%)$ & $6(54.5 \%)$ & $1.11(0.10-12.47)$ & 0.94 \\
\hline No & $8(38.1 \%)$ & $5(45.5 \%)$ & 1.00 & \\
\hline \multicolumn{5}{|l|}{ Hypertension, $n(\%)$} \\
\hline Yes & $11(54.2 \%)$ & $8(61.5 \%)$ & $0.53(0.13-2.10)$ & 0.36 \\
\hline No & $13(45.8 \%)$ & $5(38.5 \%)$ & 1.00 & \\
\hline \multicolumn{5}{|l|}{ History of preterm birth, $n(\%)$} \\
\hline Yes & $3(13.6 \%)$ & $1(12.5 \%)$ & $1.11(0.10-12.47)$ & 0.94 \\
\hline No & $19(86.4 \%)$ & $7(87.5 \%)$ & 1.00 & \\
\hline \multicolumn{5}{|l|}{ Socioeconomic characteristics } \\
\hline \multicolumn{5}{|l|}{ Education, $n(\%)$} \\
\hline Current education & $13(100 \%)$ & $16(66.7 \%)$ & 1.00 & 0.08 \\
\hline Children who left school & $0(0 \%)$ & $8(33.3 \%)$ & $13.91(0.73-263.5)$ & \\
\hline \multicolumn{5}{|l|}{ Maternal education, $n(\%)$} \\
\hline High school or less & $7(53.8 \%)$ & $19(90.5 \%)$ & $8.14(1.32-50.25)$ & 0.02 \\
\hline Bachelor's degree & $6(46.2 \%)$ & $2(9.5 \%)$ & 1.00 & \\
\hline \multicolumn{5}{|l|}{ Paternal education, $n(\%)$} \\
\hline High school or less & $4(44.4 \%)$ & $19(90.5 \%)$ & $11.88(1.67-84.52)$ & 0.01 \\
\hline Bachelor's degree & $5(55.6 \%)$ & $2(9.3 \%)$ & 1.00 & \\
\hline \multicolumn{5}{|l|}{ Main caregiver education, $n(\%)$} \\
\hline High school or less & $21(91.3 \%)$ & $8(61.5 \%)$ & $6.56(1.05-40.95)$ & 0.04 \\
\hline Bachelor's degree & $2(8.7 \%)$ & $5(38.5 \%)$ & 1.00 & \\
\hline Income $10,000 \mathrm{THB}^{\mathrm{b}} /$ month (IQR) & $4(1.6-6.0)$ & $1.5(0.8-3.0)$ & $0.51(0.29-0.88)$ & 0.02 \\
\hline
\end{tabular}

$I Q R$, interquartile range; $T H B$, Thai Baht; $C A K U T$, congenital anomalies of the kidney and urinary tract; $C K D$, chronic kidney disease

${ }^{a}$ Including dialysis and kidney transplantation

${ }^{\mathrm{b}} 10,000$ THB is equal to approximately 330 United States dollars (USD) and is expressed as the median (IQR) significant) and hypertension ( $p=0.36$, clinically significant) were selected for final model building by forward likelihood selection. KRT is a clinical factor that was associated with below-average cognitive function (OR: 6.67, 95\% CI: 1.16-38.25, $p=0.03$ ) when adjusted for anemia and hypertension. According to the multivariable logistic regression analysis of socioeconomic factors, low maternal education $(p=0.02)$, low main caregiver education ( $p=$ $0.04)$, and low family income ( $p=0.02)$ were selected for final model building using forward likelihood selection. For every 10,000 BTH increase in income (approximately 330 USD), the OR of below-average cognitive function was 0.53 (95\% CI: 0.31-0.90), $p=0.02$ ). In other words, low family income was a socioeconomic factor associated 
with below-average cognitive function when adjusted by low maternal and low main caregiver education.

\section{Relationship between risk factors and the FSIQ}

A multivariable linear regression analysis using the enter method (Table 4) was performed to investigate the relationships between risk factors and the FSIQ. Any variables that were either significant in univariable linear regression analysis $(p<0.05)$ or clinically significant were selected for multivariable linear regression analysis. Therefore, KRT ( $p$ $=0.25$, clinically significant $)$, anemia $(p=0.04)$, children who left school $(p=0.01)$, low main caregiver education $(p$ $=0.047)$, and family income $(p=0.002)$ were selected for final model building and the multivariable linear regression analysis using the enter method. The FSIQ of the group of children who had left school was 12.94 points lower than that of the currently educated group $(p=0.046)$. In addition, every 10,000 THB (approximately 330 USD) increase in family income was correlated with a 1.58 point increase in the FSIQ $(p=0.047)$. Notably, the KRT, anemia, and low main caregiver education groups had FSIQs that were 6.21, 11.06, and 13.13 points lower than those of the non-KRT, non-anemic and high main caregiver education groups, respectively, in the univariable linear regression analysis.
However, statistical significance was not found in multivariable linear regression analysis.

\section{Discussion}

This study was conducted to assess cognitive function in children with CKD in a developing country and to identify factors associated with cognitive dysfunction. The prevalence of below-average cognitive function $(F S I Q<90)$ in children with CKD in this study was high, at $64.9 \%$. Most children $(94.6 \%)$ received scores indicating below-average cognitive function in at least one cognitive domain. Children who left school and a low family income were associated with low FSIQ scores.

The children included in this study exhibited similar characteristics, and no major differences were observed when our results were compared with those of other pediatric studies including age, sex, and the etiology of CKD [6, 10, 11, 13, $15,18]$. Socioeconomic status in this study was lower than that in developed countries. In a series of cognitive studies in children with CKD in developed countries [6, 10, 11], most maternal education levels were higher than high school and more than 13 years in duration, while only $38-41 \%$ of the children had mothers with education levels of high school or less than high school. In contrast, this study identified a higher number of children whose mothers had low education
Table 4 Univariable and multivariable linear regression analyses of the relationships between risk factors and the FSIQ.

\begin{tabular}{|c|c|c|c|c|}
\hline \multirow[t]{2}{*}{ Characteristics } & \multicolumn{2}{|c|}{$\begin{array}{l}\text { Univariable linear regression } \\
\text { analysis }\end{array}$} & \multicolumn{2}{|c|}{$\begin{array}{l}\text { Multivariable linear regression } \\
\text { analysis }\end{array}$} \\
\hline & $\begin{array}{l}\beta \text { (unstandardized } \\
\text { coefficients) }\end{array}$ & $P$ & $\begin{array}{l}\beta \text { (unstandardized } \\
\text { coefficients) }\end{array}$ & $P$ \\
\hline Kidney replacement therapy ${ }^{a}$ & -6.21 & 0.25 & 2.11 & 0.70 \\
\hline Anemia & -11.06 & 0.04 & -1.96 & 0.75 \\
\hline CAKUT & 2.47 & 0.65 & & \\
\hline Glomerular disease & -0.44 & 0.95 & & \\
\hline Duration of CKD, years & -0.19 & 0.67 & & \\
\hline Proteinuria & -4.77 & 0.40 & & \\
\hline Hypertension & 7.78 & 0.13 & & \\
\hline History of preterm birth & -1.79 & 0.82 & & \\
\hline Children who left school & -16.07 & 0.01 & -12.94 & 0.046 \\
\hline \multicolumn{5}{|l|}{ Maternal education: } \\
\hline High school or less & -12.64 & 0.04 & & \\
\hline \multicolumn{5}{|l|}{ Main caregiver education: } \\
\hline High school or less & -13.13 & 0.047 & -4.95 & 0.48 \\
\hline Income $10,000 \mathrm{THB}^{\mathrm{b}} /$ month & 2.27 & 0.002 & 1.58 & 0.047 \\
\hline
\end{tabular}

$C A K U T$, congenital anomalies of the kidney and urinary tract; $C K D$, chronic kidney disease

${ }^{a}$ Including dialysis and transplantation

${ }^{\mathrm{b}} 10,000$ THB is equal to approximately 330 United States dollars (USD)

The $\beta$ coefficient indicates a difference in the domain z score per 1-point higher FSIQ 
levels; $76.5 \%$ had high school or less than high school education levels.

A systematic review and meta-analysis [1] of data from 9 countries in North America, Europe, and Africa demonstrated that children with CKD at any stage, including those who had undergone KT, had poorer neurocognitive function than the general population, with a mean difference in the FSIQ of -10.5 (95\% CI -13.2 to -7.72 ); the mean FSIQ of children at all CKD stages was $92.7 \pm 16.2$. In this study, the median FSIQ was lower, at 83.0 (71.0-95.0). One possible explanation is that most of the children (76.8\%) in the previous report had mild to moderate CKD, and only $23.2 \%$ of the children were receiving KRT. In contrast, higher numbers of children in this study (37.8\%) were receiving KRT. In addition, the difference may be related to environmental effects or possibly the low socioeconomic status of children in this study. Consistent with a previous report [1], children in this study had lower scores in the verbal, visual, and executive function domains. However, the U.S. versions of the WISC-V and WAIS-III were used in this study. The tests used an IQ measure normalized in the U.S., therefore, the tests cannot rule out the possibility that cognitive functioning skewed low because of the cultural bias of the WISC and WAIS. Previous studies of FSIQ measurement in Thai children have been reported, but they used the Thai version of the WISC-III [26-30]. The mean FSIQ using the Thai version of the WISC-III was 93-96, 97, 90, and 79 in healthy children, liver transplant recipients, children with a history of preterm birth, and children with prenatally-acquired human immunodeficiency virus (HIV), respectively [26-30].

A comparison of cognitive dysfunction in children with CKD included in previous pediatric series is difficult to compare because the definitions of cognitive dysfunction, CKD stages, sample sizes, inclusion and exclusion criteria, and cognitive evaluation tools varied. This study used the U.S. version of the WISC-V for children from 6-16 years of age and the WIAS-III for adolescents aged 17-18 years and showed that the prevalence of below-average cognitive function $(F S I Q<90)$ and cognitive impairment $(F S I Q<70)$ was $64.9 \%$ and $24.3 \%$, respectively. A total of $27.0 \%$ of the children in this study had below-average cognitive function, including children in the mild to moderate CKD group.

Anemia is a common condition in children with CKD. The mechanisms of cognitive dysfunction in patients with anemia are thought to be related to impairment of cerebral blood flow and oxygen metabolism leading to chronic brain damage [31]. Anemia in both adults with CKD and general pediatric patients has been associated with long-term neurological consequences [25, 32]. However, data on the relationship between cognitive dysfunction and anemia in children with CKD are limited, and some studies have shown a lack of an association $[13,33]$. In the univariable logistic regression analysis, anemia (OR: 4.88, 95\% CI: 1.01-23.57) was a potential factor associated with below-average cognitive function in the present study; however, it did not maintain significance in the multivariable logistic regression analysis, probably due to the small sample size.

A study in adults [34] showed that patients who underwent KT had better cognitive function than those on chronic dialysis. In addition, children with CKD had a mean IQ increase of approximately 12 points after undergoing KT [35]. This may be due to improved kidney function and the subsequent reduction in neurotoxins in the brain [14, 35]. Similarly, this study demonstrated that children who underwent KT had higher median FSIQ scores than children who were on chronic dialysis (84.0 (71.9-87.8)) in the KT group vs. 70.5 (64.0-89.3) in the dialysis group). In addition, KRT was a clinical factor associated with below-average cognitive function (OR: 6.67, 95\% CI: 1.16-38.25) in this study when adjusted for anemia and hypertension. Other potential risk factors reported in previous pediatric studies [6, 9-13] were greater CKD severity, younger age at kidney disease onset, hypertension, and low birth weight, which were not statistically significant in this study.

Studies in adults with CKD stage 5D on hemodialysis $[15,16]$ showed a relationship between low socioeconomic status and cognitive impairment. Additionally, there was an association between lower education attainment and adverse health outcomes in adults with CKD [36]. Consistent with previous studies of adults $[15,16,36]$, children who left school and a low family income were associated with low cognitive function in this study. A review by Groothoff et al. [37] revealed that children with CKD stage 5D and KRT had significantly lower cognitive function in adulthood and a lower level of education attainment than children in the control group. Consistent with this hypothesis, the FSIQ of the group of children who had left school was 12.94 points lower than that of the currently educated group. This could be because the currently uneducated children lacked participation in proper cognition-promoting activities that tend to occur at school. Although education at public schools is free for Thai children until grade 9, the main reasons for school dropout in this study were falling behind academically after frequent school absences, frequent hospital visits, traveling difficulty due to physical disabilities and parental concerns regarding their child's health. This study is the first report in a developing country to demonstrate that low family income was associated with low cognitive function. Every 10,000 THB (approximately 330 USD) increase in family income was correlated with a 1.58-point increase in the FSIQ in the present study. Previous studies in children with CKD $[6,10]$ demonstrated relationships between maternal education and cognitive dysfunction. Low main caregiver education was not related to cognitive dysfunction in the present study, although low main caregiver education was significantly associated with a 13.13-point lower FSIQ score in 
the univariable linear regression analysis. However, it did not maintain statistical significance in multivariable linear regression analysis.

This study has several strengths. First, this is the first report in a developing country to assess cognitive function in children with CKD, revealing a high prevalence of below-average cognitive function in children with CKD. Children in developing countries have different socioeconomic statuses from those in developed countries. Many of them have several risks that affect cognitive function, such as poor health, malnutrition, lack of education, and lack of stimulation at home. Therefore, these results expand on those in the literature. Second, this study is homogenous in terms of cognitive assessment because the same tool was used for all children. Third, this study identified socioeconomic risk factors associated with low cognitive function, especially low family income, which had not been reported in prior pediatric studies in developing countries. Our study also has several limitations. First, relatively few patients were included in this study, which limited the statistical analysis of risk factors of interest. However, this is only one of a few studies that assessed full cognitive function and socioeconomic risk factors in children with CKD, especially in a developing country. Second, there was a potential for significant selection bias due to the number of eligible participants who chose not to participate. Sixty-two children who met the inclusion criteria declined to participate due to awareness of the risks of COVID-19, which was a potential selection bias; perhaps more educated parents or those with a higher income were more aware of the risks of COVID-19 and had a higher rate of declining, or perhaps children with more transportation or resource barriers were less likely to participate. Third, the cross-sectional design did not allow the evaluation of changes in cognitive function over time. Fourth, this study included diverse CKD stages, from mild to moderate CKD to KRT, so the results were not specific to a certain group. Additionally, we were unable to perform subgroup analysis due to the small patient numbers. Fifth, the U.S. versions of the WISC-V and WAIS-III were used in this study. The tests used an IQ measure normalized for the U.S. population, and this study did not include a healthy, unaffected control group with which to assess the effect of using the tests; therefore, the tests cannot exclude the possibility that cognitive functioning skewed low because of the cultural bias of the WISC-V and WAIS-III. Therefore, further prospective longitudinal studies to compare cognitive function over time and increased sample sizes are required to validate the findings of this study.

In conclusion, this study demonstrated a high prevalence of cognitive dysfunction in children with CKD in a developing country. Children who left school and a low family income were strongly associated with low FSIQs. We suggest that cognitive dysfunction should be identified early in high-risk children with CKD, and specialized services should be provided when needed.

Acknowledgements The author is grateful to Miss Maturin Juntongsree of the Department of Pediatrics for her assistance with participant recruitment.

Author contribution Elawin Viriyapak designed the work, collected the data, performed the analysis, interpreted the data, drafted the initial manuscript, and approved the final manuscript as submitted. Sasitorn Chantaratin and Thanaporn Chaiyapak made substantial contributions to the conception of the study, designed the work, interpreted the data, revised the work critically for important intellectual content, and approved the final manuscript as submitted. Kanokwan Sommai performed the analysis, revised the work critically for important intellectual content, and approved the final manuscript as submitted. Achra Sumboonnanonda, Anirut Pattaragarn, Suroj Supavekin, Nuntawan Piyaphanee, and Kraisoon Lomjansook interpreted the data, revised the work critically for important intellectual content, and approved the final manuscript as submitted

Funding This study was funded by the Research Department, Faculty of Medicine, Mahidol University, Bangkok, Thailand, Grant Number (IO) R016331012.

\section{Declarations}

Ethics approval This study was approved by the Siriraj Hospital Ethics Board.

Consent to participate Informed consent and assent were obtained from all parents and participants, respectively.

Consent for publication Not applicable.

Competing interests The authors declare no competing interests.

\section{References}

1. Chen K, Didsbury M, Van Zwieten A, Howell M et al (2018) Neurocognitive and educational outcomes in children and adolescents with CKD: a systematic review and meta-analysis. Clin J Am Soc Nephrol 13:387-397. https://doi.org/10.2215/CJN.09650917

2. Drew DA, Weiner DE, Sarnak MJ (2019) Cognitive impairment in CKD: pathophysiology, management, and prevention. Am J Kidney Dis 74:782-790. https://doi.org/10.1053/j.ajkd.2019.05. 017

3. Chadban SJ, Ahn C, Axelrod DA, Foster BJ et al (2020) KDIGO clinical practice guideline on the evaluation and management of candidates for kidney transplantation. Transplantation 104:S11S103. https://doi.org/10.1097/tp.0000000000003136

4. Gerson AC, Butler R, Moxey-Mims M, Wentz A, Shinnar S, Lande MB, Mendley SR, Warady BA, Furth SL, Hooper SR (2006) Neurocognitive outcomes in children with chronic kidney disease: current findings and contemporary endeavors. Ment Retard Dev Disabil Res Rev 12:208-215. https://doi.org/10.1002/ mrdd. 20116

5. Haavisto A, Korkman M, Holmberg C, Jalanko H, Qvist E (2012) Neuropsychological profile of children with kidney transplants. Nephrol Dial Transplant 27:2594-2601. https:// doi.org/10.1093/ndt/gfr650 
6. Brouhard BH, Donaldson LA, Lawry KW, McGowan KR, Drotar D, Davis I, Rose S, Cohn RA, Tejani A (2000) Cognitive functioning in children on dialysis and post-transplantation. Pediatr Transplant 4:261-267. https://doi.org/10.1034/j.13993046.2000.00121.x

7. Gipson DS, Duquette PJ, Icard PF, Hooper SR (2007) The central nervous system in childhood chronic kidney disease. Pediatr Nephrol 22:1703-1710. https://doi.org/10.1007/ s00467-006-0269-1

8. Matsuda-Abedini M, Fitzpatrick K, Harrell WR, Gipson DS, Hooper SR, Belger A, Poskitt K, Miller SP, Bjornson BH (2018) Brain abnormalities in children and adolescents with chronic kidney disease. Pediatr Res 84:387-392. https://doi.org/10.1038/ s41390-018-0037-5

9. Lande MB, Mendley SR, Matheson MB, Shinnar S, Gerson AC, Samuels JA, Warady BA, Furth SL, Hooper SR (2016) Association of blood pressure variability and neurocognition in children with chronic kidney disease. Pediatr Nephrol 31:2137-2144. https://doi.org/10.1007/s00467-016-3425-2

10. Hooper SR, Gerson AC, Butler RW, Gipson DS, Mendley SR, Lande MB, Shinnar S, Wentz A, Matheson M, Cox C, Furth SL, Warady BA (2011) Neurocognitive functioning of children and adolescents with mild-to-moderate chronic kidney disease. Clin J Am Soc Nephrol 6:1824-1830. https://doi.org/10.2215/CJN. 09751110

11. Ruebner RL, Laney N, Kim JY, Hartung EA, Hooper SR, Radcliffe J, Furth SL (2016) Neurocognitive dysfunction in children, adolescents, and young adults with CKD. Am J Kidney Dis 67:567-575. https://doi.org/10.1053/j.ajkd.2015.08.025

12. Kogon AJ, Kim JY, Laney N, Radcliffe J, Hooper SR, Furth SL, Hartung EA (2019) Depression and neurocognitive dysfunction in pediatric and young adult chronic kidney disease. Pediatr Nephrol 34:1575-1582. https://doi.org/10.1007/s00467-019-04265-Z

13. Slickers J, Duquette P, Hooper S, Gipson D (2007) Clinical predictors of neurocognitive deficits in children with chronic kidney disease. Pediatr Nephrol 22:565-572. https://doi.org/10.1007/ s00467-006-0374-1

14. Viggiano D, Wagner CA, Martino G, Nedergaard M, Zoccali C, Unwin R, Capasso G (2020) Mechanisms of cognitive dysfunction in CKD. Nat Rev Nephrol 16:452-469. https://doi.org/10.1038/ s41581-020-0266-9

15. Joseph SJ, Bhandari SS, Dutta S (2019) Cognitive impairment and its correlates in chronic kidney disease patients undergoing haemodialysis. J Evol Med Dent Sci 8:2818-2822. https://doi.org/ 10.14260/jemds/2019/611

16. Gesualdo GD, Duarte JG, Zazzetta MS, Kusumota L, Say KG, Pavarini SCI, Orlandi FS (2017) Cognitive impairment of patients with chronic renal disease on hemodialysis and its relationship with sociodemographic and clinical characteristics. Dement Neuropsychol 11:221-226. https://doi.org/10.1590/1980-57642016dn 11-030003

17. Qvist E, Pihko H, Fagerudd P, Valanne L, Lamminranta S, Karikoski J, Sainio K, Rönnholm K, Jalanko H, Holmberg C (2002) Neurodevelopmental outcome in high-risk patients after renal transplantation in early childhood. Pediatr Transplant 6:53-62. https://doi.org/10.1034/j.1399-3046.2002.1o040.x

18. Mendley SR, Matheson MB, Shinnar S, Lande MB, Gerson AC, Butler RW, Warady BA, Furth SL, Hooper SR (2015) Duration of chronic kidney disease reduces attention and executive function in pediatric patients. Kidney Int 87:800-806. https://doi.org/10. 1038/ki.2014.323

19. The World Bank (2021) Classification of economies. https://datah elpdesk.worldbank.org/knowledgebase/articles/906519-worldbank-country-and-lending-groups. Accessed 16 May 2021.

20. Grantham-McGregor S, Cheung YB, Cueto S, Glewwe P, Richter L, Strupp B (2007) Developmental potential in the first 5 years for children in developing countries. Lancet 369:60-70. https://doi. org/10.1016/s0140-6736(07)60032-4

21. Schwartz GJ, Muñoz A, Schneider MF, Mak RH, Kaskel F, Warady BA, Furth SL (2009) New equations to estimate GFR in children with CKD. J Am Soc Nephrol 20:629-637. https://doi. org/10.1681/asn.2008030287

22. White CT, Gowrishankar M, Feber J, Yiu V (2006) Clinical practice guidelines for pediatric peritoneal dialysis. Pediatr Nephrol 21:1059-1066. https://doi.org/10.1007/s00467-006-0099-1

23. Hemodialysis Adequacy 2006 Work Group (2006) Clinical practice guidelines for hemodialysis adequacy, update 2006. Am J Kidney Dis 48:S2-S90. https://doi.org/10.1053/j.ajkd.2006.03. 051

24. Levin A, Stevens PE, Bilous RW, Coresh J, De Francisco AL, De Jong PE, Griffith KE, Hemmelgarn BR, Iseki K, Lamb EJ (2012) Kidney disease: improving global outcomes (KDIGO) CKD work group. KDIGO 2012 clinical practice guideline for the evaluation and management of chronic kidney disease. Kidney Int Suppl 3:1-150

25. Allali S, Brousse V, Sacri AS, Chalumeau M, De Montalembert M (2017) Anemia in children: prevalence, causes, diagnostic workup, and long-term consequences. Expert Rev Hematol 10:10231028. https://doi.org/10.1080/17474086.2017.1354696

26. Getsuwan S, Chuthapisith J, Treepongkaruna S, Butsriphum N, Prabpram W, Charoenthanakit C, Tanpowpong P, Lertudomphonwanit C (2021) Behavior problems and cognitive function in pediatric liver transplant recipients. Transplant Proc 53:649-655. https://doi.org/10.1016/j.transproceed.2020.10.041

27. Pongcharoen T, DiGirolamo AM, Ramakrishnan U, Winichagoon P, Flores R, Martorell R (2011) Long-term effects of iron and zinc supplementation during infancy on cognitive function at $9 \mathrm{y}$ of age in Northeast Thai children: a follow-up study. Am J Clin Nutr 93:636-643. https://doi.org/10.3945/ajen.110.002220

28. Kerr SJ, Puthanakit T, Vibol U, Aurpibul L et al (2014) Neurodevelopmental outcomes in HIV-exposed-uninfected children versus those not exposed to HIV. AIDS Care 26:1327-1335. https://doi. org/10.1080/09540121.2014.920949

29. Piriyapokin N, Chuthapisith J, Emrat K, Nuntnarumit P (2020) Outcomes of preterm infants born with marginal viability in a University Hospital in Thailand. J Paediatr Child Health 56:943949. https://doi.org/10.1111/jpc.14782

30. Puthanakit T, Aurpibul L, Louthrenoo O, Tapanya P, Nadsasarn R, Insee-Ard S, Sirisanthana V (2010) Poor cognitive functioning of school-aged children in thailand with perinatally acquired HIV infection taking antiretroviral therapy. AIDS Patient Care STDS 24:141-146. https://doi.org/10.1089/apc.2009.0314

31. Kuwabara Y, Sasaki M, Hirakata H, Koga H, Nakagawa M, Chen T, Kaneko K, Masuda K, Fujishima M (2002) Cerebral blood flow and vasodilatory capacity in anemia secondary to chronic renal failure. Kidney Int 61:564-569. https://doi.org/10.1046/j. 1523-1755.2002.00142.x

32. Stivelman JC (2000) Benefits of anaemia treatment on cognitive function. Nephrol Dial Transplant 15(Suppl 3):29-35. https://doi. org/10.1093/oxfordjournals.ndt.a027973

33. Kalaitzidis RG, Karasavvidou D, Tatsioni A, Balafa O, Pappas K, Spanos G, Pelidou SH, Siamopoulos KC (2013) Risk factors for cognitive dysfunction in CKD and hypertensive subjects. Int Urol Nephrol 45:1637-1646. https://doi.org/10.1007/ s11255-013-0450-y

34. Ozcan H, Yucel A, Avsar UZ, Cankaya E, Yucel N, Gozubuyuk H, Eren F, Keles M, Aydinli B (2015) Kidney transplantation is superior to hemodialysis and peritoneal dialysis in terms of cognitive function, anxiety, and depression symptoms in chronic kidney disease. Transplant Proc 47:1348-1351. https://doi.org/10.1016/j. transproceed.2015.04.032 
35. Icard P, Hooper SR, Gipson DS, Ferris ME (2010) Cognitive improvement in children with CKD after transplant. Pediatr Transplant 14:887-890. https://doi.org/10.1111/j.1399-3046. 2010.01359.x

36. Morton RL, Schlackow I, Staplin N, Gray A, Cass A, Haynes R, Emberson J, Herrington W, Landray MJ, Baigent C, Mihaylova B, Sharp Collaborative Group (2016) Impact of educational attainment on health outcomes in moderate to severe CKD. Am J Kidney Dis 67:31-39. https://doi.org/10.1053/j.ajkd.2015.07.021

37. Groothoff JW, Grootenhuis M, Dommerholt A, Gruppen MP, Offringa M, Heymans HS (2002) Impaired cognition and schooling in adults with end stage renal disease since childhood. Arch Dis Child 87:380-385. https://doi.org/10.1136/adc.87.5.380

Publisher's note Springer Nature remains neutral with regard to jurisdictional claims in published maps and institutional affiliations. 